\title{
O MICROCRÉDITO NO BRASIL E O SEU PAPEL NO DESENVOLVIMENTO DOS PEQUENOS NEGÓCIOS
}

\author{
Lindson Douglas de Sousa Vasconcelos ${ }^{1}$ \\ Luis de Sousa Lima Junior ${ }^{2}$
}

RESUMO: $O$ desemprego se apresenta como uma das principais causas do empreendedorismo, principalmente em tempos de pandemia, como o que vivemos atualmente. $\mathrm{O}$ microcrédito se mostra como uma fonte de recursos alternativa para pequenos empreendedores sejam eles formais ou informais, como uma ferramenta auxiliar para o combate à pobreza e à exclusão social. No Brasil, o microcrédito é amplamente utilizado como ferramenta de interesse governamental, com apoio dos governos Municipal, Estadual e Federal. Desse modo, o presente artigo visa mostrar a evolução do microcrédito tanto no mundo quanto no Brasil, bem como suas contribuições para combater a informalidade e as dificuldades de acesso ao crédito.

Palavras-chave: Microcrédito. Empreendedorismo. Pequenos negócios.

\section{INTRODUÇÃO}

O microcrédito é o termo que utilizamos para designar financiamentos com característica um empréstimo de pequeno valor, direcionado para pessoas com baixa renda e de classes sociais menos favorecidas, com interesse em iniciar um pequeno negócio, porém possuem pouco ou nenhum acesso a formas convencionais de crédito.

O intuito desse tipo de crédito é ser um instrumento de geração de renda e trabalho, promovendo a inclusão social de pessoas localizadas nas margens do processo produtivo.

$\mathrm{O}$ microcrédito surge como um gerador de emprego e renda para essas pessoas, financiando pequenos negócios formais e permitindo e fornecendo as condições necessárias para as pessoas sem recursos financeiros, com a finalidade de impulsionar o início do negócio, por mais simples que ele seja - artesanato, costura, doces caseiros e artesanais, pães, vendedores ambulantes, entre outros.

Desse modo, o microcrédito se apresenta como uma ferramenta utilizada para sanar necessidades financeiras para aqueles sem acesso aos sistemas convencionais de crédito.

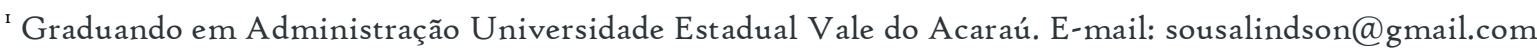

${ }^{2}$ Graduando em Administração Instituição: Universidade Estadual Vale do Acaraú
} 

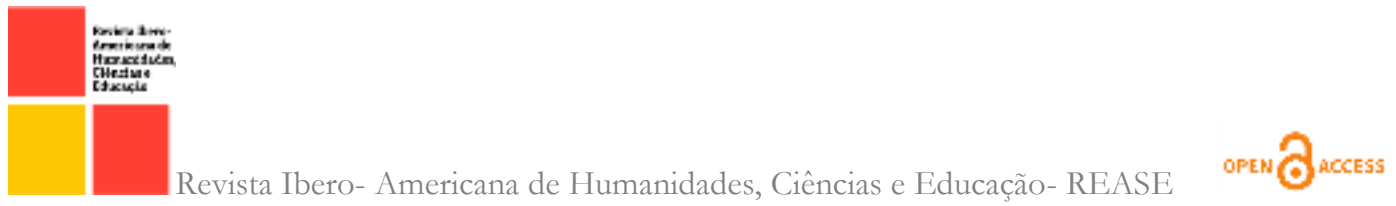

Portanto, o intuito do presente artigo é mostrar como os benefícios e o papel do microcrédito no desenvolvimento de pequenos negócios, passando pelos principais conceitos que permeiam a área, bem como sua história no Brasil, mostrando a importância do microcrédito para o desenvolvimento de empreendedores, por meio de um estudo de caso do cenário empreendedor, se utilizando de fontes evidenciais quantitativas.

\section{REFERENCIAL TEORICO}

\section{I.I Histórico do microcrédito no mundo e no Brasil}

O empreendedorismo não depende de raça, cor ou classe social, englobando tanto as grandes empresas quanto os pequenos negócios. Porém, para empreender, se faz necessário ter recursos financeiros.

O microcrédito surgiu da necessidade de criação de alternativas de crédito para pessoas, físicas ou jurídicas, do setor formal e informal, que possuíam pouco ou nenhum acesso ao sistema bancário tradicional de modo a obter um financiamento, porém possuíam desejo montar, ampliar ou obter capital de giro para seu pequeno negócio.

Em 1976, Muhammad Yunus, professor do departamento de Economia Rural da Universidade de Chittagong em Bangladesh, passou a emprestar dinheiro após verificar um grande contingente de pessoas envolvidas em atividades informais no país - em Bangladesh, um terço da população vivia, na época, com menos de US\$I (um dólar) por dia, sendo considerado um dos países mais pobres do mundo, ao mesmo passo em que era um dos países com maior população do mundo (YUNUS, 2003).

Essas pessoas não eram pobres por estupidez ou por preguiça. Elas trabalhavam o dia inteiro, realizando tarefas físicas muito complexas. Eram pobres porque as estruturas financeiras de nosso país não tinham a disposição de ajuda-las a melhorar sua sorte. Era um problema estrutural, e não um problema individual”. (YUNUS, 2002, p.24)

Com isso, Yunus passou a negociar empréstimos em parceria com um banco da cidade, em nome da população pobre, se tornando fiador deles. Com essa ação, se iniciou a fase experimental da criação de uma instituição voltada para a concessão de empréstimos à população pobre. Em 1978, surgia o Grameen Bank, responsável por emprestar um total de 2,4 bilhões de dólares em microcrédito para mais de 2,5 milhões de empreendedores, de modo que possam ampliar suas oportunidades para realizar seus negócios. 
Desse modo, pessoas excluídas do sistema financeiro tradicional são capazes de desenvolver condições socioeconômicas, dinamizando seus empreendimentos.

Para o país, o microcrédito trouxe o crescimento da renda das famílias beneficiadas pelo empréstimo, com um terço saindo da linha da pobreza, enquanto os outros dois terços se encaminham para isso; as crianças do país estão bem nutridas; houve uma enorme melhora na alfabetização e na moradia, além da mortalidade infantil ter reduzido.

Essa iniciativa chegou na América Latina nos anos 8o, começando pelo Peru, Chile e Bolívia, por meio da criação de organizações não governamentais - ONGs e cooperativas que concediam empréstimos para microempresários com baixo rendimento.

Abaixo, trazemos a definição de microcrédito segundo Rosales (2002) em dois países da América Latina - Bolívia e Colômbia:

Quadro I - Faturamento Anual de Empresas

\section{Bolívia}

No país, microcrédito é definido como um crédito concedido ao indivíduo ou entidade jurídica, ou até mesmo a um grupo de mutuários, assumindo diversas responsabilidades por meio de empréstimo reembolso, que é destinado ao financiamento de uma pequena produção, comercialização ou atividades relacionadas a serviços, sendo a principal fonte de pagamento tanto do produto de vendas quanto das receitas geradas por tais atividades. Esses créditos, ao serem aprovados, devem ser apoiados por uma verificação, fazendo uma análise da situação financeira do mutuário, de modo a mostrar a capacidade de reembolso do mesmo, levando em consideração sua real capacidade de honrar com as responsabilidades assumidas, no caso de haver omissão ou falta de pagamento por parte de um ou mais codevedores. A análise deve incluir o pedido de relatórios $\mathrm{m}$ fontes de informações de crédito. 


\section{Colômbia}

RAs instituições sob supervisão da Superintendência classificam o microcrédito como um conjunto de ativos das operações de crédito, concedido à microempresas, com um saldo de dívida com a instituição não excedente a 25 vez o salário mínimo mensal atual. Por microempresa, se entende toda e qualquer unidade de exploração econômica, que seja operada por um indivíduo ou entidade jurídica, exercendo atividades empresariais, agrícolas, comerciais, além de serviços rurais ou urbanos, com salários referentes a dez trabalhadores e um total de ativos de quinhentos e uma vezes o salário mínimo mensal atual.

Fonte: ROSALES (2002)

As micro e pequenas empresas tinham pouco acesso a créditos na América Latina. Em países como Brasil, Argentina, Uruguai, México e Venezuela, o número de microempresários é alto, porém a taxa de penetração nesses países é inferior a $1 \%$ (YUNUS, 2002).

No Brasil, a lei Ir.IIo, de 25 de abril de 2005, foi responsável por instituir o Programa

Nacional de Microcrédito Produtivo e Orientado (PNMPO), conceituando o microcrédito da seguinte maneira:

[...] concedido para o atendimento das necessidades financeiras de pessoas físicas e jurídicas empreendedoras de atividades produtivas de pequeno porte, utilizando metodologia baseada no relaciona - mento direto com os empreendedores no local onde é executada a atividade econômica. ( $\left(3^{\circ}\right.$ do art. $\left.\mathrm{I}^{\circ}\right)$

O PNMPO tem como objetivo:

- Incentivar a criação de trabalho e renda para microempreendedores populares;

- Disponibilizar os recursos necessários para o microcrédito;

- Oferecer apoio técnico para as instituições de microcrédito, visando seu fortalecimento institucional.

Logo, o PNMPO é destinado para microempreendedores, formais e informais aqueles com atividades produtivas de pequeno porte, com faturamento anual de até $\mathrm{R} \$ 120$ mil. 
Segundo Neri (2005, p.43), o mercado de crédito brasileiro oferece mais privilégios para o consumidor do que para o produtor, com foco no curto prazo e na alta renda. A falta de capital faz com que pessoas de baixa renda não tenham acesso ao crédito formal, fazendo com que seus ativos tenham um baixo valor de mercado.

O BNDES - Banco Nacional de Desenvolvimento Econômico e Social é o responsável por definir o microcrédito como a concessão de empréstimos, de pequenos valores, para microempreendedores formais e informais, que possuam pouco ou nenhum acesso ao sistema tradicional. Essa concessão é feita de maneira assistida, com o agente de crédito visitando o local do empreendimento de modo a avaliar as necessidades do mesmo e as condições para utilização do crédito.

Inicialmente, o microcrédito no Brasil teve início em 1973, no Recife, quando o Programa Uno pela União Nordestina de Assistência a Pequenas Organizações foi desenvolvido. Essa iniciativa ganhou força nos anos 8o, um período caracterizado por um crescimento baixo da economia, alta inflação, a perda do poder de compra, a escassez de crédito, reduzindo de maneira drástica o número de trabalhos formais e aumentando as desigualdades econômicas e sociais no país.

$\mathrm{Na}$ década de 90 o desempenho do mercado de trabalho brasileiro foi desastroso. As aberturas comercial e financeira indiscriminadas, os elevados juros, as privatizações e a sobrevalorização do real favoreceram a ocorrência do mais baixo crescimento econômico do Brasil no século XX, em meio à desestruturação da produção e do emprego doméstico. Neste quadro, as taxas de desemprego mais que dobraram (atingindo um em cada cinco trabalhadores das grandes cidades), foram queimados mais de três milhões de empregos formais e a informalidade e a precarização das condições de trabalho alcançou cerca de dois em cada cinco trabalhadores." (MATTOSO, 2000, p. Io).

Diante desse contexto, as organizações se preocuparam em reverter tal situação, passando a conceder empréstimos para microempreendedores.

A escassez de crédito é muito mais severa para os micros e pequenos empreendimentos. Com isso, há uma restrição considerável de sua capacidade produtiva, que ocasiona um impacto negativo na geração de receitas e na ampliação de suas atividades, cuja consequência é o surgimento de um ciclo econômico-financeiro restritivo". (CAVALCANTE, 2004).

A oferta de acesso ao crédito, através da disseminação do microcrédito, é uma alternativa viável para o desenvolvimento de pequenos negócios. 
Quadro 2-Faturamento Anual de Empresas

\begin{tabular}{|c|c|c|c|c|c|}
\hline Ano & $\begin{array}{l}\text { Número de } \\
\text { clientes } \\
\text { atendidos }\end{array}$ & $\begin{array}{l}\text { Número de } \\
\text { operações de } \\
\text { microcrédito } \\
\text { realizadas }\end{array}$ & $\begin{array}{c}\text { Variação } \\
\text { anual }\end{array}$ & $\begin{array}{l}\text { Valores nominais } \\
\text { concedidos ( } \mathrm{R} \$ \text { ) }\end{array}$ & $\begin{array}{c}\text { Valores atualizados } \\
\text { concedidos }(\mathrm{R} \$)\end{array}$ \\
\hline 2008 & I.430.097 & 1.280 .680 & 0,00 & $1.825 \cdot 147 \cdot 592,77$ & $3.028 .311 .115,98$ \\
\hline 2009 & I.654.186 & I.620.656 & $26,55 \%$ & $2.323 .599 .790,69$ & $3.620 .727 .053,21$ \\
\hline 2010 & 2.071 .607 & I. 966.718 & $21,35 \%$ & $2.998 .623 .914,48$ & $4 \cdot 448 \cdot 115 \cdot 368,16$ \\
\hline 2011 & 2.674 .157 & 2.576 .559 & $31,01 \%$ & $4.098 .289 \cdot 416,62$ & $5.761 .258 .770,63$ \\
\hline 2012 & 3.953 .406 & $3.8 \mathrm{I} 4.78 \mathrm{I}$ & $48,06 \%$ & $6.504 .785 .890,40$ & $8.620 .138 .678,68$ \\
\hline 2013 & $5.664 .94 \mathrm{I}$ & 5.713 .091 & $49,76 \%$ & 10.162.675.000,69 & I2.681.328.919,6I \\
\hline 2014 & 5.552 .080 & 5.667 .287 & $-0,80 \%$ & II.646.316.132,59 & $13 \cdot 767 \cdot 209 \cdot 554,90$ \\
\hline 2015 & $5.200 .78 \mathrm{I}$ & 5.201 .992 & $-8,21 \%$ & II.107.086.670,62 & I2.359.966.047,07 \\
\hline
\end{tabular}

Os dados apresentados acima são baseados no panorama do microcrédito divulgado pelo Banco Central do Brasil (BCB) em 2015, com base em dados disponíveis no Sistema de Informações de Créditos (SCR).

\subsection{O empreendedorismo e as micro e pequenas empresas no Brasil}

O empreendedorismo deve ser abordado para entendermos a importância da concessão de créditos, justamente por ser direcionado aos empreendedores. $O$ empreendedorismo é um agente de mudanças locais, pois a criação de uma empresa e/ou o seu desenvolvimento gerando reflexos para toda a região em que está inserida (JULIEN, 2010).

[...] impulsiona rapidamente a região a evoluir, para finalmente se desenvolver e responder melhor às necessidades de seus cidadãos $e$ de clientes externos, criando mais empresas no seu seio, consequentemente mais empregos e mais riqueza e, finalmente, mais desenvolvimento regional (JULIEN, 2010, p. 17).

Os empreendedores, de maneira geral, contribuem de maneira positiva para a sociedade, pois utilizam as oportunidades que aparecem, de modo a prover bens e serviços 
e gerar novas oportunidades e empregos. O empreendedor é aquele que assume os riscos de se começar uma empresa (MAXIMIANO, 2006).

Segundo o IBGE (2010), as micro e pequenas empresas compõem o setor de maior representatividade do país. O Serviço Brasileiro de Apoio às Micro e Pequenas Empresas Sebrae separa os pequenos negócios em segmentos, de acordo com a faixa de faturamento, de acordo com a Lei Complementar 123/2006 - Lei Geral das Micro e Pequenas Empresas.

Quadro 3 - Faturamento Anual de Empresas

\begin{tabular}{cc}
\hline Classificação & Faturamento Anual \\
\hline Microempreendedor Individual & Até R\$60 mil \\
Microempresa & Até R $\$ 360$ mil \\
Empresa de Pequeno Porte & Até R\$3,6 milhões \\
\hline
\end{tabular}

Fonte: SEBRAE, 2010

Em 2010, o número de micro e pequenas tinha chegado a 6,1 milhões de estabelecimentos ativos, gerando mais de 14,5 milhões de postos de trabalhos. Isso corresponde a $99 \%$ de todos os estabelecimentos do país, gerando $51 \%$ dos empregos formais.

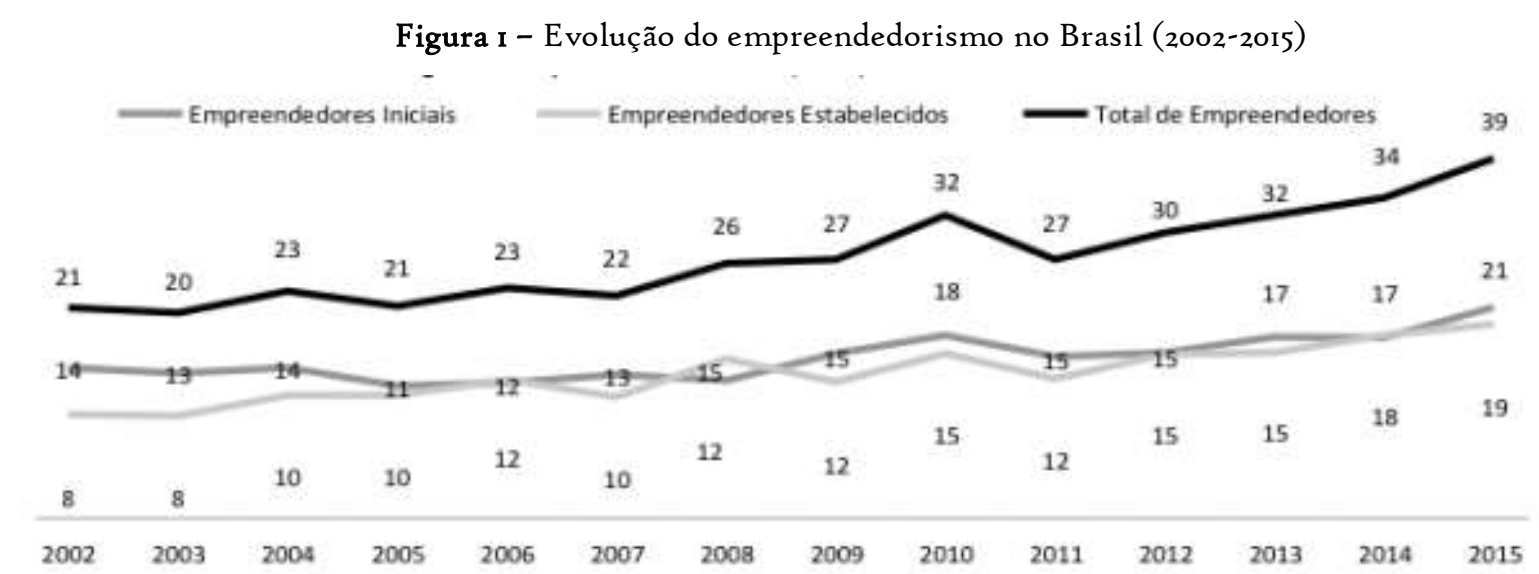

Fonte: Elaborado a partir de dados do IBGE (2010)

Sobre a informalidade, entendendo-se que uma empresa informal é a que não tem um sistema de contas separado de maneira clara das contas da família, empregando até cinco pessoas, o IBGE constatou que em 2010 havia 13,8 milhões de trabalhadores na informalidade, um total de $25 \%$ da população ocupada no país. 
Das vagas criadas no setor informal, $69 \%$ pertencia a trabalhadores por conta própria, I0\% trabalhavam sem carteira assinada, I0\% de empregadores e 6\% trabalhavam com carteira assinada, além de5\% de trabalhadores não remunerados, conforme trazemos na figura abaixo:

Figura 2 - Informalidade do mercado

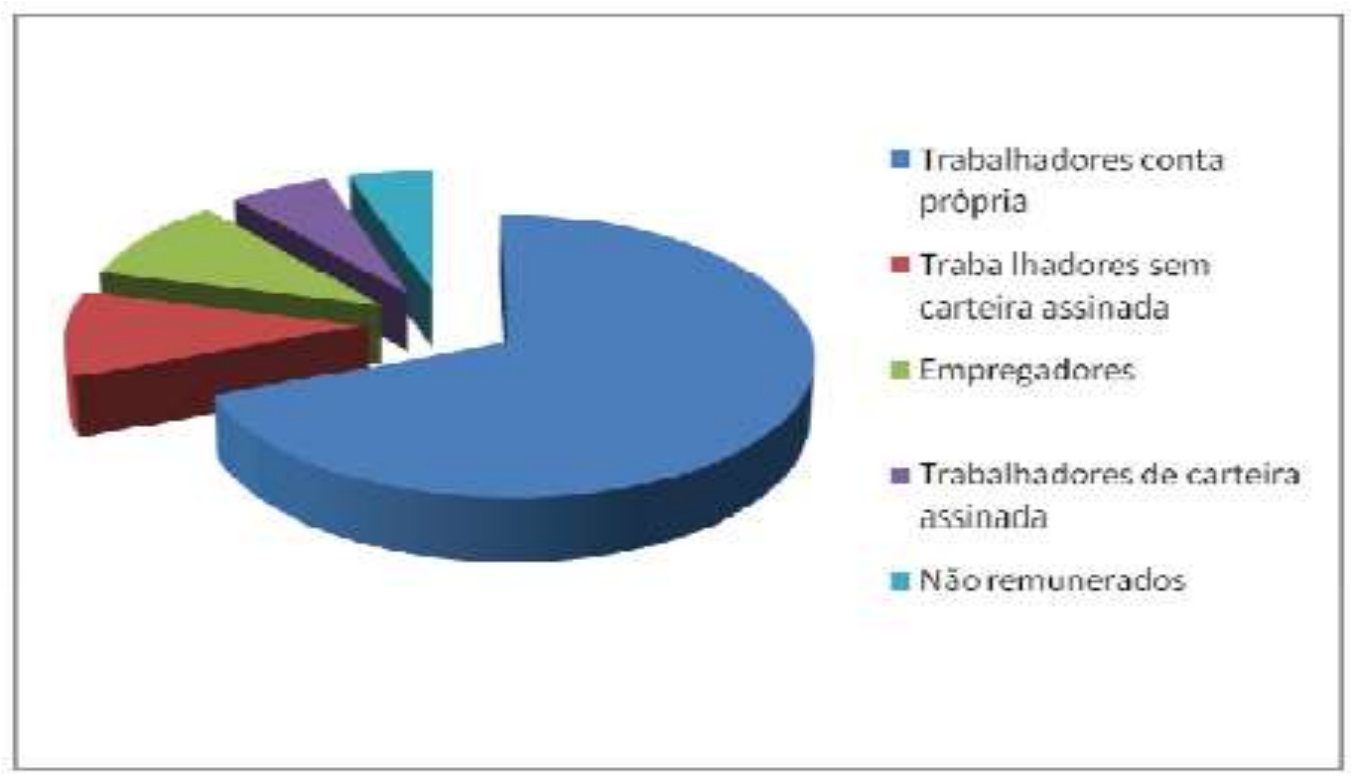

Fonte: Elaborado a partir de dados do IBGE (2010)

Ainda segundo o IBGE, a maioria das empresas informais não se utiliza de créditos, tendo como principal fonte de recurso os bancos públicos e privados.

O início das atividades desses empreendimentos é marcado por diversas dificuldades. Ainda, muitos estabelecimentos não conseguem crescer ou não chegam ao primeiro ano de vida, encerrando suas atividades de maneira precoce.

De acordo com o Sebrae, $76 \%$ das empresas criadas no país conseguem sobreviver aos primeiros dois anos de vida, um número que tem mostrado um crescimento aos poucos. A região Sudeste aparece em primeiro lugar no ranking por região, com um índice de $78 \%$, com a região Sul em segundo lugar, com $75 \%$ de sobrevivência.

Se faz importante ter um estudo voltado para o meio, principalmente se levarmos em conta que as micro e pequenas empresas são as principais beneficiárias de programas 
que facilitam o acesso a créditos por parte dos pequenos negócios, que talvez não conseguiriam de maneira tradicional.

O sistema financeiro não atende a todas as necessidades de micro e pequenas empresas e a falta de garantias é apontada como um dos principais obstáculos que deve ser superado por empresários de modo a se obter recursos. Do mesmo modo, as instituições financeiras apresentam dificuldades em reduzir os riscos das operações por conta da falta de garantia e de informações confiáveis acerca do negócio.

\section{METODOLOGIA}

A abordagem qualitativa tem como objetivo conhecer as particularidades dos fatos, bem como eles ocorrem e sua influências no processo de desenvolvimento do programa de microcrédito. A abordagem descritiva tem como objetivo descrever uma população ou um fato, que estão sob observação do estudo.

A pesquisa exploratória aproxima o pesquisador do tema abordado, constituindo uma ferramenta que cria grande familiaridade entre o tema e o fenômeno investigado, proporcionando uma visão maior acerca do fenômeno (GIL, 2002). Faz-se necessário explorar de modo a se criar uma aproximação e uma familiaridade com os fatos e os fenômenos por meio de levantamento bibliográficos, entrevistas, entre outros (SANTOS, 1999).

O artigo está baseado na bibliografia que encontramos referentes ao tema, no intuito de apresentar aspectos acerca do que já foi estudado sobre o assunto, aumentando a possibilidade de se obter novas e inovadoras conclusões.

Os procedimentos técnicos consistem em pesquisas de levantamento bibliográfico e documental, cuja principal vantagem é o fato de permitir o investigador a cobertura de fenômenos de uma maneira ampla (GIL, 2006).

$\mathrm{Na}$ pesquisa bibliográfica feita, em materiais já publicados, em livros, artigos, teses e dissertações, procuramos trazer os principais conceitos relacionados à microcréditos e micro e pequenas empresas, de modo a mostrar a importância do microcrédito para o desenvolvimento de pequenos negócios no Brasil. 

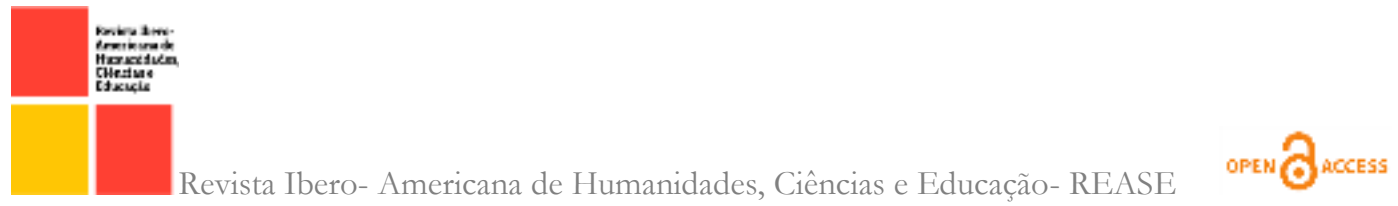

As questões de pesquisas utilizadas no presente artigo buscam responder os impactos do microcrédito que é recebido pelo empreendedor.

\section{ANÁLISE E DISCUSSÃO}

O microcrédito busca atender um público que enfrenta dificuldades no acesso aos sistemas tradicionais de crédito. Parente (2002) se utilizou da seguinte ilustração para demonstrar essa dificuldade:

- Io grupo - pessoas que possuem cartão de crédito;

- $2^{\mathrm{o}}$ grupo - pessoas que não possuem cartão de crédito. Porém gostariam de ter;

- $3^{\circ}$ grupo - os que não possuem cartão de crédito.

O segundo grupo, apesar de demonstrar o mesmo padrão de consumo do primeiro grupo, não atende às exigências das operadoras de cartão de crédito para serem contemplados com um cartão. Isso origina nesse grupo uma frustração, bem como um sentimento de exclusão, até mesmo maior do que no terceiro grupo, por eles saberem que têm condições de ter um cartão, mas não se encaixarem nas exigências para ter um de fato (SEN, 1995).

A baixa renda é uma característica do público-alvo do microcrédito - a renda é considerada suficiente caso a pessoa possa criar condições e tenha capacidade de ocupar determinada posição dentro do ambiente produtivo em que vive.

Logo, o público-alvo do microcrédito são empreendedores, proprietários de microempresas, agricultores e trabalhadores autônomos. É um segmento dinâmico e capaz de reprodução, gerando trabalho e rendas para as famílias, possibilitando a competição dentro de certos nichos do mercado.

As micro e pequenas empresas sempre apresentaram maior dificuldade de acesso ao crédito, visto que os controles ainda são informais e as atividades não possuem custos apurados, nem projeções futura, o que dificulta o trabalho com bancos tradicionais, por conta do grande risco de se oferecer crédito, o que leva a propostas de investimento serem barradas, dificultando ainda o acesso ao capital de giro. 
Poucos recursos, altas taxas de juros, dificuldades na elaboração de um bom projeto de investimento faz com que os pequenos negócios tenham dificuldade em ter acesso ao crédito, influenciando de maneira direta na obtenção e na manutenção da competitividade.

Sob essa luz, surge o Sebrae para facilitar o acesso de pequenos negócios ao crédito e ao capital necessários, de maneira pioneira. O Sebrae recomenda a busca de motivos para a contração de créditos, a partir da seguinte análise:

- Verificar as vantagens de pegar dinheiro emprestado do banco, só fazendo caso esteja realmente seguro de que a empresa tem condições para pagá-lo dentro do período;

- Verificar se o financiamento é viável para o sucesso da empresa;

- Ter em mente que a obtenção de um financiamento no intuito de cobrir outro somente auxilia na contração de dívidas difíceis de serem quitadas;

- A utilização de crédito para cobrir prejuízos operacionais é totalmente vedada. $O$ crédito deve ser utilizado para expandir e fortalecer seu negócio e o capital de giro.

Além disso, se faz importante que os empreendedores estejam atentos aos

indicadores de produtividade e competitividade, como o faturamento bruto, a relação entre faturamento e o número de empregados, bem como a relação entre o faturamento e a área ocupada. Esses indicadores servem como ferramentas de análise e avaliação para os pequenos negócios.

De maneira geral, o poder público e a sociedade devem estabelecer políticas e meios que auxiliem na promoção do desenvolvimento econômico e social, propiciando a geração de emprego e renda por meio do crédito produtivo. Como os pequenos negócios não atendem as exigências que garantem os financiamentos, tampouco as condições estabelecidas pelas instituições financeiras, os bancos comerciais, regulados e fiscalizados pelo Banco Central, relutam em colocar em prática políticas de crédito que beneficiem pequenos empreendimentos que estejam fora desses parâmetros estabelecidos.

O microcrédito, enfatizado e reconhecido pelo Banco Mundial Banco Interamericano de Desenvolvimento, UNICEF, entre outros, é o instrumento de maior alcance àqueles que buscam a promoção de mudanças sociais e inovações financeiras, 
principalmente diante de crises que o país passa. O papel que é atribuído a micro e pequenas empresas dentro do desenvolvimento econômico do país não apresenta discussão, principalmente se levarmos em conta sua importância para a geração tanto de empregos quanto de renda.

\section{CONSIDERAÇÕES FINAIS}

O microcrédito é uma alternativa para promover o desenvolvimento socioeconômico, servindo como um instrumento de auxílio para políticas que visam combater o desemprego. É visto como uma ferramenta com uso cada vez mais crescente e popular, tendo um papel relevante para empreendedores de todo o país.

Para a sua contratação, basta o empreendedor se enquadrar nos critérios fixos do programa, visto que não importa se o negócio é formal ou informal (pessoa física ou jurídica), facilitando o acesso de negócios menores e simples, por não haver exigência em relação a documentos ou demonstrações mais complexas, o que poderia dificultar a entrada de pequenos empreendedores.

O grau de adesão tem aumentado, acompanhando o aumento do número de empreendedores, que acabam buscando e contratando o microcrédito junto a sua respectiva Prefeitura. Esse aumento é observado principalmente por conta das taxas, que são menores se comparadas ao sistema tradicional de financiamento.

Logo, o microcrédito é um estímulo ao empreendedorismo, um meio de crescimento desejável para pequenos negócios, propiciando o aumento da qualidade de vida da população e promovendo o desenvolvimento econômico, visto que micro e pequenas empresas são importantes compositores da economia da sociedade.

Partindo desse ponto, a criação de linhas de crédito específicas para esse segmento se mostram de grande importância para a criação e a manutenção de pequenos negócios.

Com essas informações, visando o aprofundamento na questão, sugere-se mais estudos relacionados a importância do microcrédito para o desenvolvimento de pequenos negócios, além do desenvolvimento econômico e social dos municípios, trazendo uma visão geral acerca do assunto. 


\section{REFERÊNCIAS BIBLIOGRÁFICAS}

BANCO NACIONAL DE DESENVOLVIMENTO ECONÔMICO E SOCIAL BNDES. Disponível em: www.bndes.gov.br. Acesso em: 19-07-2021.

BRASIL, Lei № II.IIo, de 25 de abril de 2005. Disponível em: http://www.planalto.gov.br/ccivil. Acesso em: 19-07-2021.

BRASIL, Lei Complementar № I23, de I4 de dezembro de 2006. Disponível em: http://www.planalto.gov.br/ccivil. Acesso em: 19-07-202I.

BCB. Série Cidadania Financeira: Estudos sobre educação, proteção e inclusão./ - Brasília: Banco Central do Brasil, 2015. Disponível em: http://www.bcb.gov.br/?CIDADANIAFINANCEIRA. Acesso em 19-07-202I.

CAVALCANTE, André Bezerra. Microcrédito: uma alternativa de crédito produtivo para o micro e pequeno empreendedor. Disponível em http://integração.fgvsp.br/anos/15/index.htm. Acesso em 19-07-2021

GIL, Antônio Carlos. Como elaborar projetos de pesquisa. 4. ed., São Paulo, Editora Atlas, 2002.

JULIEN, Pierre-André. Empreendedorismo regional e economia do conhecimento. São Paulo: Saraiva, zoro.

MATTOSO, Jorge Eduardo Levi. Crescimento e Emprego em 200o. Monitor Mercantil, Rio de Janeiro, mai./20oo.

MAXIMIANO, Antonio Cesar Amaru. Administração para empreendedores: fundamentos da gestão e da criação de novos negócios. São Paulo: Pearson Prentice Hall, 2006.

Microcrédito - Conceito de Microcrédito. Disponível em http://www.pt.wikipedia.org/wiki/microcr\%C3\%A9dit. Acesso em 19-07-202I.

Microcrédito - História do microcrédito. Disponível em http://www.pt.wikipedia.org/wiki/microcr\%C3\%A9dit. Acesso em: 19-07-2021.

Microcrédito - Instituições que operam o microcrédito no Brasil. Disponível em: http://www.pt.wikipedia.org/wiki/microcr\%C3\%A9dito. Acesso em: 19-07-202I.

Microcrédito - $\mathrm{O}$ microcrédito no Brasil. Disponível em: http://www.credisol.org.br/microcredito. Acesso em I9-07-202I.

NERI, M.C. Microcrédito, o mistério nordestino e o grammen brasileiro. Rio de Janeiro: FGV/IBRE, CPS, 2008. Disponível em: http://www.fgv.br/cps/crediamigo. Acesso: 1907-2021.

NERI, Marcelo. Estudo do Perfil Socioeconomico dos Clientes do Crediamigo do BNB. [S.1.], 2004. Disponível em: http://www.jusbrasil.com.br/noticias/I66o7o/governorealiza-programa-de-microcredito-produtivo-orientado. Acesso em: 19-07-2021.

NERI, Marcelo. Políticas Públicas aos pequenos produtores. Revista Conjuntura Econômica. [S.1.], 2005.

PNMPO. Programa Nacional do Microcrédito Produtivo Orientado (PNMPO). Disponível em http://trabalho.gov.br/empreendedorismo/pnmpo. Acesso em I9-07-202I. ROSALES, Ramon. "Tendencias recientes en la regulación del financiamiento a la microempresa". Presented at the 5th Inter-American Forum on Microenterprise, 2002. ROSALES, Ramón. Marco jurídico para as instituições de microcrédito .In: SEMINÁRIO INTERNACIONAL BNDES 
MICROFINANÇAS. 20oo, Rio de Janeiro. Anais...Rio de Janeiro: BNDES, 2000. SEBRAE - Serviço Brasileiro de Apoio às Micro e Pequenas Empresas. http://www.sebrae.com.br/PortalSebrae/sebraeaz/Microcrédito. Acesso em: 19-07-2021. SEBRAE. $O$ que é o Microcrédito. Disponível em: http://www.uasf.sebrae.com.br/uasfareas/uasfmicrocredito/microog/defmc. Acesso em: 19-07-2021

SEBRAE. O que é o Microcrédito. O papel do Microcrédito no desenvolvimento econômico e social. Disponível em: http://www.uasf.sebrae.com.br/uasfareas/uasfmicrocredito/microog/ppmic. Acesso em: I9-07-2021.

SEBRAE. O que é o Microcrédito. Microcrédito contribui para ocupação e geração de renda. Agencia SEBRAE de Notícias: os pequenos negócios em pauta. 21/05/2009. Disponível em: http://asn.interjornal.com.br/noticia. $\mathrm{kmf}$ ?noticia $=8466252 \& \mathrm{canal}=210 \&$ total $=429 \&$ indice $=$ o. Acesso em: 19-07-202I.

SEN, Amartya. Desenvolvimento com liberdade. (200o) In: SOUZA, Maria C. Garcia F. O desenho do Programa CrediAmigo do Banco do Nordeste: inclusão social e mercado. Fortaleza: BNB, 2010.

YUNUS, Muhammad. O Banqueiro dos Pobres. Iํㅡㄹ. ed. São Paulo, Editora Ática, 2002. 